\section{SAT0529 SHORT-TERM EFFICACY AND SAFETY OF BIOSIMILAR RITUXIMAB IN PATIENTS WITH SYSTEMIC VASCULITIDES}

I. Smitienko ${ }^{1}$, P. Novikov ${ }^{2}$, S. Moiseev ${ }^{2}$, A. Zykova ${ }^{3}$, T. Shevtsova ${ }^{3} .{ }^{1}$ Medical center K+31; ${ }^{2}$ Sechenov First Moscow State Medical University; ${ }^{3}$ Lomonosov Moscow State University, Moscow, Russian Federation

Objectives: To study efficacy and safety of biosimilar (intended copy) rituximab (Acellbia, BIOCAD) in patients with systemic vasculitides.

Methods: We enrolled in our case series all consecutive patients with systemic vasculitides diagnosed according to $\mathrm{CHCC} 2012$ and ACR criteria (if applicable) who were treated with biosimilar rituximab since 2015. Activity of vasculitis was evaluated using BVAS3. CD19+ B-cells count was measured by standard method. Patients received intravenous rituximab at a $500 \mathrm{mg}$ dose (four weekly infusions for remission induction or two weekly every 6 months infusions for maintenance treatment)

Results: In total, 45 patients were treated with biosimilar rituximab (29 GPA, 12 MPA, 1 EGPA, 2 cryoglobulemic vasculitis, 1 rheumatoid vasculitis). In 12 patients (7 GPA, 3 MPA, 1 CryoVas, 1 RheumVas), rituximab was administered for induction of remission due to high activity and relapsing course of vasculitis and low efficacy of previous treatment. 33 patients (22 GPA, 9 MPA, 1 EGPA, 1 CryoVas) received rituximab for maintenance of remission. Median duration of follow-up was 12 months. ${ }^{6-26}$

At 1 and 3 months, all patients achieved B-cell depletion. At 6 months, B-cell repopulation was shown in 9 patients (20\%). Remission induction therapy with rituximab resulted in decrease of median BVAS from 16 10-24 to $1(0-4)$ at 3 months and to $0(0-2)$ at 6 months. At 3 and 6 months, median prednisone dose was tapered from $50 \mathrm{mg} 35-80$ to $25 \mathrm{mg} 15-40$ and $10 \mathrm{mg}, 5-20$ respectively. In patients who received rituximab for maintenance treatment, median BVAS showed no disease activity $(0-1)$ both at baseline and at 3 or 6 months. At baseline and at 3 months median doses of prednisolone were $5 \mathrm{mg}(0-7.5)$ and $5 \mathrm{mg}$ $(0-5)$. At 6 months, it was reduced to $2.5 \mathrm{mg}(0-5)$. Biosimilar rituximab had acceptable safety profile. Adverse events included mild infusion reaction, ${ }^{2}$ urinary ${ }^{3}$ and bronchopulmonary ${ }^{5}$ infections which required intravenous antibiotics (median 4 months after infusions), hypogammaglobulinemia ${ }^{2}$ that persisted for at least 12 months and 1 case of late-onset neutropenia in 8 months.

Conclusions: Biosimilar rituximab showed high efficacy and acceptable safety in patients with systemic vasculitides.

Disclosure of Interest: None declared

DOI: 10.1136/annrheumdis-2018-eular.5488

\section{SAT0530 CLINICAL FEATURES ASSOCIATION WITH HLA-B ALLELIC TYPES (B27, B51) IN KOREAN PATIENTS OF BEHCET'S DISEASE}

J.H. Kim, J.H. Jung, S.J. Choi, Y.H. Lee, J.D. Ji, G.G. Song. Internal medicine, KOREA University Medical Center, Seoul, Korea, Republic Of

Background: The recurrent oral ulcer frequently occur as a first clinical manifestation of Behcet's disease (BD), but BD is characterised by considerable phenotypic variation, comprising a myriad of manifestations, e.g. recurrent genital ulcers and skin, joint, eye, vascular and/or CNS involvement. BD is well known to be associated with HLA-B51 antigen. HLA B27 antigen is famous for association with spondyloarthropathy. But BD is also observed in HLA B27 positive patients.

Objectives: The aim of this study was to clarify the clinical features association with HLA-B antigens (B27, B51) in Korean patients of Behcet's disease.

Methods: We genotyped HLA-B alleles in 433 patients who showed recurrent oral ulcer. The diagnosis of $\mathrm{BD}$ was determined according to revised international study group criteria. Among them, 126 patients of BD were included. The genotyping was performed using 66 sets of sequence specific DNA probe (PCR-SSP). The clinical feature was assessed according to HLA B allele in the patients diagnosed with $B D$.

Results: HLA-B51 allele frequency was more frequent in both 126 BD patients and 433 total patients and the frequency was $40(31.7 \%)$ and $110(25,4 \%)$ respectively. Among the HLA B51 +BD patients $(n=40)$, similar gender ratio was observed (Male $52.5 \%$, Female $47.5 \%$ ) and clinical features of diagnostic criteria were dominant. Among the HLA B27 +BD patients $(n=17)$, genital ulcer and skin lesions were dominant. HLA B27 +B51+BD patient was one and clinical features were genital ulcer, skin lesion and arthritis.

Conclusions: The specific clinical features of BD were observed in HLAB51 +BD patients. In HLA B27 +BD patients, genital ulcer and skin lesions were more observed. The study about clinical features associated with HLA-B allele (B27, B51) in spondyloarthropathy patients is also needed.

\section{REFERENCES:}

[1] Hamzaoui A, Houman MH, Massouadia M, et al. Contribution of Hla-B51 in the susceptibility and specific clinical features of Behcet's disease in Tunisian patients. Eur J Intern Med 2012;23(4):347-9.

[2] Sakly N, Boumiza R, Zrour-Hassen S, et al. HLA-B27 and HLA-B51 determination in Tunisian healthy subjects and patients with suspectedankylosing spondylitis and Behçet's disease. Ann N Y Acad Sci 2009;1173:564-9.

[3] Montes-Cano MA, Conde-Jaldón M, García-Lozano JR, et al. HLA and non-HLA genes in Behçet's disease: a multicentric study in the Spanish population. Arthritis Res Ther 2013;15(5):R145.

[4] Maldini C, Lavalley MP, Cheminant M, et al. Relationships of HLA-B51 or B5 genotype with Behcet's disease clinical characteristics: systematic review and meta-analyses of observational studies. Rheumatology (Oxford) 2012;51(5):887-900.

Disclosure of Interest: None declared

DOI: 10.1136/annrheumdis-2018-eular.6728

\section{SAT0531 ACUTE PHASE REACTANT LEVELS AND PREDNISONE DOSES AT DISEASE FLARE IN PATIENTS WITH GIANT CELL ARTERITIS: PROSPECTIVE DATA FROM THE GIACTA TRIAL}

J.H. Stone ${ }^{1}$, K. Tuckwell ${ }^{2}$, S. Dimonaco ${ }^{3}$, M. Klearman ${ }^{2}$, M. Aringer ${ }^{4}$,

D. Blockmans ${ }^{5}$, E. Brouwer ${ }^{6}$, M.C. Cid ${ }^{7}$, B. Dasgupta ${ }^{8}$, J. Rech ${ }^{9}$, C. Salvarani ${ }^{10}$, H. Schulze-Koops s1, G. Schett ${ }^{12}$, R. Spiera ${ }^{13}$, S.H. Unizony ${ }^{1}$, N. Collinson ${ }^{3}$ on behalf of GiACTA Investigators. ${ }^{1}$ Massachusetts Gen Hosp Rheumatol Unit, Harvard Med School, Boston; ${ }^{2}$ Genentech, South San Francisco, USA; ${ }^{3}$ Roche Products Ltd, Welwyn Garden City, UK; ${ }^{4}$ Abteilung für Rheumatologie, Dresden, Germany, ${ }^{5}$ University Hospitals Gasthuisberg, Leuven, Belgium; ${ }^{6}$ University of Gröningen, University Medical Center, Gröningen, Netherlands; ${ }^{7}$ University of Barcelona, Institut d'Investigacions Biomèdiques August Pi i Sunyer, Barcelona, Spain; ${ }^{8}$ Southend University Hospital, NHS Foundation Trust, Westcliff-on-Sea, UK; ${ }^{9}$ Friedrich-Alexander-U Erlangen-Nürnberg, Erlangen, Germany; ${ }^{10}$ Arcispedale Santa Maria Nuova-IRCCS, Reggio Emilia, Italy, ${ }^{11}$ University of Munich, Munich;

${ }^{12}$ Universitätsklinikum Erlangen, Erlangen, Germany; ${ }^{13}$ Hospital for Special Surgery, Cornell, USA

Background: The relationship between acute phase reactant levels and giant cell arteritis (GCA) disease flares is not known, particularly in the era of interleukin-6 receptor blockade with tocilizumab (TCZ). Prednisone doses at which GCA flares can occur have not been studied thoroughly in prospective clinical trials. Objectives: Investigate prednisone doses and acute phase reactant levels at the time of disease flare in patients with GCA.

Methods: Secondary analyses of prednisone doses, C-reactive protein (CRP) levels, and erythrocyte sedimentation rate (ESR) were performed for patients who experienced GCA flare after achieving remission during 52 weeks of treatment with TCZ-weekly or -every-other-week+26 week prednisone taper (TCZ-QW or TCZ-Q2W) or placebo +26 week or 52 week prednisone taper (PBO+26 or PBO +52 ). The last CRP and ESR values before first disease flare were used if values on the day of first flare were missing. Analyses are descriptive and were performed post hoc.

Results: GCA flare after remission was reported in $23 \%(23 / 100)$ of TCZ-QW patients, 26\% (13/50) of TCZ-Q2W patients, 68\% (34/50) of PBO +26 patients, and $49 \%(25 / 51)$ of $\mathrm{PBO}+52$ patients. ${ }^{1}$ Median CRP levels and ESR at the time of flare were lower in the TCZ groups than in the PBO groups (Table). In the TCZ groups, $92 \%(33 / 36)$ of flares were associated with normal CRP levels ( $\leq 1 \mathrm{mg} / \mathrm{dL}$ ) and $89 \%(32 / 36)$ were associated with normal ESR values $(<30 \mathrm{~mm} / \mathrm{h})$. In the PBO groups, 34\% (20/59) of flares were associated with normal CRP values and $31 \%(18 / 59)$ with normal ESR. Median (min-max) prednisone doses at the time of disease flare in the combined TCZ and combined PBO groups were $5.5(0.0-$ $310.0)$ and $9.0(0.0-55.0) \mathrm{mg} /$ day, respectively. Among 149 patients in the TCZ groups, $10(7 \%)$ had disease flares while receiving prednisone doses greater than $10 \mathrm{mg} /$ day, accounting for $28 \%$ of all disease flares in the TCZ groups. Among 101 patients in the PBO groups, $23(23 \%)$ had disease flares while receiving prednisone doses $>10 \mathrm{mg} /$ day, accounting for $39 \%$ of all disease flares in the PBO groups. Thus, 33 of the 95 disease flares in GiACTA (35\%) occurred while the patient was receiving $\geq 10 \mathrm{mg} /$ day prednisone. 
Abstract SAT0531 - Table 1. Prednisone doses and acute phase reactants at GCA flare

\begin{tabular}{|c|c|c|c|c|}
\hline & $\begin{array}{c}\text { TCZ-QW } \\
\mathrm{N}=100\end{array}$ & $\begin{array}{c}\text { TCZ-Q2W } \\
\mathrm{N}=49\end{array}$ & $\begin{array}{c}\mathrm{PBO}+26 \\
\mathrm{~N}=50\end{array}$ & $\begin{array}{c}\mathrm{PBO}+52 \\
\mathrm{~N}=51\end{array}$ \\
\hline $\begin{array}{l}\text { Patients who experienced } \\
\text { flare, } \mathrm{n}(\%)^{\mathrm{a}}\end{array}$ & $23(23)$ & $13(27)$ & $34(68)$ & $25(49)$ \\
\hline $\begin{array}{l}\text { Median (min-max) prednisone } \\
\text { dose at flare, mg }\end{array}$ & $\begin{array}{c}7.0 \\
(0.0-30.0)\end{array}$ & $\begin{array}{c}2.0 \\
(0.0-310.0)\end{array}$ & $\begin{array}{c}6.5 \\
(0.0-55.0)\end{array}$ & $\begin{array}{c}10.0 \\
(2.0-40.0)^{\mathrm{e}}\end{array}$ \\
\hline \multicolumn{5}{|c|}{ Patients who experienced first flare while on prednisone dose, $\mathrm{mg} /$ day, $\mathrm{n}(\%)^{\mathrm{a}}$} \\
\hline 0 & $5(5.0)$ & $4(8.0)$ & $9(18.0)$ & 0 \\
\hline $1-5$ & $5(5.0)$ & $4(8.0)$ & $7(14.0)$ & $5(9.8)$ \\
\hline$>5-10$ & $5(5.0)$ & $3(6.0)$ & $4(8.0)$ & $10(19.6)$ \\
\hline$>10-20$ & $5(5.0)$ & $1(2.0)$ & $9(18.0)$ & $8(15.7)$ \\
\hline$>20-30$ & $3(3.0)$ & 0 & $2(4.0)$ & 0 \\
\hline$>30-40$ & 0 & 0 & $2(4.0)$ & $1(2.0)$ \\
\hline$>50-60$ & 0 & 0 & $1(2.0)$ & 0 \\
\hline$>60$ & 0 & $1(2.0)$ & 0 & 0 \\
\hline Median (min-max) CRP, ${ }^{b} \mathrm{mg} / \mathrm{L}$ & $\begin{array}{c}0.4 \\
(0.2-93.2)\end{array}$ & $\begin{array}{c}1.0 \\
(0.2-18.1)\end{array}$ & $\begin{array}{c}23.1 \\
(1.4-119.0)\end{array}$ & $\begin{array}{c}17.3 \\
(0.2-122.0)\end{array}$ \\
\hline $\begin{array}{l}\text { Flare patients with elevated } \\
\mathrm{CRP}^{\mathrm{b}} \mathrm{n}(\%)^{\mathrm{c}}\end{array}$ & 1 (4) & $2(15)$ & $22(65)$ & $17(68)$ \\
\hline $\begin{array}{l}\text { Median (min-max) ESR, } \\
\mathrm{mm} / \mathrm{h}\end{array}$ & $\begin{array}{c}5.0 \\
(0.0-80.0)\end{array}$ & $\begin{array}{c}5.0 \\
(1.0-43.0)\end{array}$ & $\begin{array}{c}51.0 \\
(8.0-140.0)\end{array}$ & $\begin{array}{c}39.0 \\
(4.0-138.0)\end{array}$ \\
\hline $\begin{array}{l}\text { Flare patients with elevated } \\
\text { ESR, }{ }^{d} \mathrm{n}(\%)^{\mathrm{c}}\end{array}$ & $1(4)$ & $3(23)$ & $27(79)$ & $14(56)$ \\
\hline
\end{tabular}

Conclusions: Acute phase reactants are not reliable correlates of disease flare in TCZ-treated patients, but approximately one-third of all PBO +prednisone patients also had normal acute phase reactants at the time of disease flare. Median prednisone dose at the time of disease flare for TCZ-treated patients was numerically lower than that of patients treated with PBO + prednisone. One-third of all disease flares in GiACTA occurred while the patient was receiving $>10 \mathrm{mg} /$ day prednisone.

\section{REFERENCE:}

[1] Stone JH, et al. N Engl J Med 2017;377:317-328.

Acknowledgements: This study was sponsored by F. Hoffmann-La Roche Ltd. Disclosure of Interest: J. Stone Grant/research support from: Roche, Genentech, Xencor, Consultant for: Roche, Genentech, Xencor, K. Tuckwell Shareholder of: Roche, Employee of: Genentech, S. Dimonaco Employee of: Roche, M. Klearman Employee of: Genentech, M. Aringer Consultant for: Chugai, Roche, Speakers bureau: Chugai, Roche, D. Blockmans: None declared, E. Brouwer Grant/research support from: Roche, M. C. Cid Consultant for: Roche, Novartis, Boehringer-Ingelheim, B. Dasgupta Consultant for: Roche, GlaxoSmithKline, J. Rech: None declared, C. Salvarani: None declared, H. Schulze-Koops: None declared, G. Schett Grant/research support from: AbbVie, BMS, Celgene, Chugai, GSK, Lilly, Novartis, Roche, Sanofi, UCB, Consultant for: AbbVie, BMS, Celgene, Chugai, GSK, Lilly, Novartis, Roche, Sanofi, UCB, R. Spiera Grant/research support from: Roche/Genentech, Consultant for: Roche/Genentech, S. H. Unizony: None declared, N. Collinson Employee of: Roche

DOI: 10.1136/annrheumdis-2018-eular.2719

\section{SAT0532 TREATMENT WITH METHOTREXATE AND RISK OF ISCHAEMIC RELAPSES IN PATIENTS WITH GIANT CELL ARTERITIS IN CLINICAL PRACTICE}

J. Font Urgelles $^{1}$, Z. Rosales Rosado ${ }^{1}$, D.D. Freites Núñez ${ }^{2}$, P.M. Lois bermejo ${ }^{1}$, L. León Mateos $^{2}$, I.C. Morado Quiñoa ${ }^{1}$, E. Pato Cour ${ }^{1}$, J.A. Jover Jover ${ }^{1}$, L. Abásolo Alcázar ${ }^{2}{ }^{1}$ Rheumatology, Hospital ClíNico San Carlos; ${ }^{2}$ Instituto De Investigaciones Sanitarias San Carlos, Madrid, Spain

Background: Clinical trials show the efficacy of Methotrexate (MTX) in giant cell arteritis (GCA). It is necessary to corroborate these results in real life.

Objectives: To assess the incidence and the risk of ischaemic relapses in GCA patients treated with and without Methotrexate (MTX) in clinical practice.

Methods: Retrospective longitudinal observational study. Subjects: patients treated at the Rheumatology Service of the Hospital Clínico San Carlos with the diagnosis of GCA. They were included from the date of diagnosis (January 1991 to September 2013) and followed-up until lost of follow up or Sept-2014. Main outcome: relapses by isquemic event (RIE): Presence of mandibular claudication, visual manifestations (blurred vision, diplopia, transient or permanent loss of vision), cerebrovascular accident, ischaemic heart disease or claudication of limbs, after having achieved an objective improvement, associated with an increase in the erythrocyte sedimentation rate (ESR) and the need to increase corticosteroids (at least $10 \mathrm{mg}$ over the previous dose). Independent variable: exposure to MTX over time. Secondary variables: sociodemographic, clinical and treatment. Statistical analysis: RIE rates were assessed by survival techniques, expressing the incidence per 100 patients ${ }^{*}$ year with their $95 \%$ confidence interval $[\mathrm{Cl}$. The influence of MTX on the REI was analysed by multivariate Cox regression models. Results were expressed as Hazard ratios (HR) with their respective Cl.

Results: 168 patients were included with a follow-up of 675.59 patients ${ }^{*} y e a r$. $80.36 \%$ were women (mean age: $76.77 \pm 7$ years). The most prevalent comorbidities were arterial hypertension (64\%), dyslipidemia (34\%), cardiovascular pathology $(30 \%)$ and polymyalgia rheumatica $(13.77 \%)$. The most common clinical symptom at diagnosis was headache $(87.43 \%)$, systemic involvement $(55 \%)$ and polymyalgia rheumatica (49.70\%). The ESR was $78 \pm 30.85 \mathrm{mmHg}$ and $\mathrm{Hb}$ of $12.06 \pm 1.58 \mathrm{mg} / \mathrm{dL}$. $46.39 \%$ had a positive biopsy. $64 \%$ were on MTX (mean dose: $10 \mathrm{mg}$ ) at any time during the follow-up, from those $68 \%$ started MTX in the first 4 weeks after diagnosis. The mean dose of corticosteroids was 50.72 $\pm 15.46 \mathrm{mg}$. There were 21 relapses by ischaemic events $(12.5 \%)$, with an incidence of 3.1 [2.02-4.77]. The median time to first RIE was 0.4 [p25-75: 0.4-5.1] years. The incidence of RIE in patients exposed to MTX was 1.92 [0.8-4.62], whereas in those without MTX was 3.84 [2.36-6.28]. The incidence of REI in women was 3.44 [2.17-5.46] and in men was 1.97 [0.6-6]. In the multivariate analysis after adjusting for age, sex, disease activity and calendar time, exposure to MTX had less risk of relapse by ischaemic event compared to those without MTX (HR 0.3 [0.096-0.99]; $p=0.048$ ).

Conclusions: The frequency of REI was $12.5 \%$. The incidence of REI was $3 \%$ patients-year. With the results observed in this study, the use of MTX seems to decrease the risk of relapses by ischaemic event.

Disclosure of Interest: None declared

DOI: 10.1136/annrheumdis-2018-eular.2690

\section{SAT0533 \\ POLVAS - RETROSPECTIVE REGISTRY OF POLISH PATIENTS WITH ANCA-ASSOCIATED VASCULITIDES}

K. Wójcik ${ }^{1}$, J. Kur-Zalewska ${ }^{2}$, A. Masiak ${ }^{3}$, A. Dębska-Ślizieńn ${ }^{3}$, J. Jeleniewicz ${ }^{4}$, K. Jakuszko ${ }^{5}$, P. Głuszko ${ }^{6}$, M. Wisłowska ${ }^{7}$, I. Brzosko ${ }^{8}$, A. Hawrot-Kawecka ${ }^{9}$, J. Musiał ${ }^{1}$ on behalf of POLVAS. ${ }^{1}$ Jagiellonian University Medical Collage, Kraków; ${ }^{2}$ Military Institute of Medicine, Warszawa; ${ }^{3}$ Medical University of Gdańsk, Gdańsk; ${ }^{4}$ Medical University of Lublin, Lublin; ${ }^{5}$ Wroclaw Medical University, Wrocław,

${ }^{6}$ National Institute of Geriatrics, Rheumatology and Rehabilitation; ${ }^{7}$ Central Clinical Hospital MSWiA, Warszawa; ${ }^{8}$ Pomeranian Medical University, Szczecin; ${ }^{9}$ Medical University of Silesia, Katowice, Poland

Background: Vascultides are a heterogeneous group of rare diseases with unknown etiology and the clinical spectrum ranging from life-threatening systemic disease to minor isolated skin changes. Present nomenclature and definitions of systemic vasculitides have been proposed in 2012 at the International Chapel Hill Consensus Conference. ${ }^{1}$ Antineutrophil cytoplasmic antibody (ANCA)-associated vasculitides (AAV) belong to the small to medium-size vessel systemic diseases comprising granulomatosis with polyangitis (GPA), microscopic polyangiitis (MPA) and eosinophilic granulomatosis with polyangiitis (EGPA).

Objectives: We decided to retrospectively analyse a large cohort of Polish AAV patients coming from referral centres - members of the Scientific Consortium of the Polish Vasculitis Registry (POLVAS)..$^{2,3}$

Methods: We conducted a systematic multicenter retrospective study of adult patients diagnosed with AAV between Jan 1990 and Dec 2016 Patients were enrolled to the study by 9 referral centres ( 14 clinical wards: - rheumatology - 10 , nephrology -2 , metabolic diseases -1 , clinical immunology -1) from 7 Voivodships populated by $22,3 \mathrm{mln}$ inhabitants $(58,2 \%$ of the Polish population). Patient data have been collected according to the uniform protocol in the POLVAS registry.

Results: Distribution of AAV in the Polish population resembles that of north European cohorts. ${ }^{4}$ In POLVAS registry 417 (66.7\%) patients were diagnosed with GPA, $106(17.0 \%)$ with MPA and $102(16,3 \%)$ with EGPA. Male-to-female ratios were almost 1:1 for GPA (210/207) and MPA (54/52), but EGPA wasd twice more frequent among women (34/68). Clinical manifestations and organ involvement were analysed both by clinical phenotype (GPA, MPA, EGPA) and ANCA specificity (anti-PR3+, and anti-MPO+)Analysis by ANCA specificity showed no apparent difference as compared to phenotype analysis. Clinical manifestations 